\title{
GLANDESTINIDAD Y LITERATURA EN EL SETECIENTOS
}

El 14 de junio de 1684, Carlos II, por Real Decreto, ordenaba al Obispo Gobernador del Consejo que recogiera las licencias otorgadas para imprimir gacetas, "pues -dice el monarca- estos días se ha aumentado este abuso con demasía. Por lo que toca a relaciones sueltas y otros papeles o coplas que suelen vender los ciegos, que no se publique ni imprima ninguna sin que se reconozca por un Consejero de Estado como se hacía antes". Años después, su sucesor, el borbón Felipe $V$, tuvo que ser aún más específico y en 1716 aludir directamente al papel menudo que escapaba toda censura en Aragón, Valencia y Cataluña, como sabemos, zonas rebeldes seguidoras de los Austrias durante la Guerra de Sucesión. El oficio que el Rey envía al marqués de Casafuerte, Teniente Comandante General del Reyno de Aragón, no deja lugar a dudas sobre las inquietudes de la Corona ante el auge de publicaciones clandestinas, ya que se

... imprimen y reimprimen oculta y cautelosamente libros de todas las facultades sin las licencias y aprobaciones requeridas por las leyes de estos reinos [...] y porque de este pernicioso abuso pueden resultar muy perjudiciales consecuencias contra la pureza de nuestra religión, buenas costumbres y regalías de la Corona... ${ }^{1}$

"Oculta y cautelosamente" los impresores, cuyo número aumenta progresivamente a lo largo del siglo xvin, dan a luz toda suerte de obras: desde gacetas de avisos y pedimentos fiscales, hasta libros, folletos y un sinfín de pliegos sueltos representantes de la literatura de cordel -romances, "historias", vidas de santos, almanaques, noticias, calendarios. Con estos pliegos, el pueblo alimentaba su apetito de poesía, novela, historia. Este afán de novedades no

1 Archivo Histórico Nacional de Madrid (en adelante A.H.N.), Consejos, 50625. Leí una versión muy reducida de este trabajo en la Fifth Annual Meeting of the American Society for Eighteenth-Century Studies, Universidad de Pennsylvania, abril, 1973. 
pasó inadvertido. Un anónimo editor de mediados del seiscientos, en picante diálogo con el lector, prologa una "noticia" y subraya el deseo de leer papeles entre los sectores populares:

Véote tan aficionado (amigo vulgo) a comprar, leer, y aun a guardar como en archivo todas las relaciones que se presentan, ya en domingo, ya en día de fiesta, que me hallo obligado a advertirte (para que a lo menos no te quejes que vendemos gato por liebre) cómo todas o la mayor parte de ellas no son más que unas bien o mal compuestas novelas, que el ciego piensa a la tarde, hace imprimir a la noche y te vende por la mañana, y aún algunas tan disparatadas como tú habrás reparado hartas veces ${ }^{2}$.

Este texto pone de relieve el hecho de que la literatura como objeto de consumo se va delineando ya nítidamente en el siglo xvn e irrumpirá con mayor fuerza en el siguiente siglo.

Precisamente porque el consumo del libro va creciendo, el gobierno - como hemos visto- toma medidas para vigilar más de cerca cuanto se publica. Clandestino adquiere entonces dos acepciones: una puramente legal que significa imprimir sin permiso, tasa y fe de erratas o privilegios cualquier género de obras, ya fueran éstas innocuos breviarios o libros de rezo; y otra acepción de carácter ideológico y político, puesto que en la clandestinidad, en total o parcial anonimato, se publicaba la literatura no oficial y de protesta en la que se perfilaba el germen de una opinión pública en los albores de la Ilustración ${ }^{3}$.

A continuación analizaré el contenido de algunas de estas obras clandestinas refiriéndome, al mismo tiempo, a las diversas disposi-

2 Apud Pascual de Gayangos, Carta de algunos Padres de la Compañia de Jesús sobre los sucesos de la monarquia. Año de 1634-1648, Memorial Histórico Español, t. 16, 1861, p. xi. Prólogos de este cariz son muy frecuentes. La literatura de cordel y pliegos sueltos han sido estudiados por Julio Caro Baroja, Ensayo sobre la literatura de cordel, Madrid, 1969 y más recientemente por María Gruz García de EnTerría, Sociedad y poesia de cordel en el barroco, Madrid, 1974. Véase también de María Teresa Pérez Picazo, La publicística española en la Guerra de Sucesión, Madrid, 1966, y de JeANFrançors Botrel, "Les aveugles colporteurs d'imprimés en Espagne", $M C V$, 9 (1973), 417-476, documentado estudio sobre la Hermandad de Ciegos.

\& Véase el interesante libro de Teófanes Egido, Opinión pública y oposición al poder en la España del siglo xuiii (1713-1759), Valladolid, 1971, y su reciente edición de Sátiras politicas de la España moderna, Madrid, 1973. Ambos estudios se centran en material manuscrito de la B.N.M; pero no alude a prohibiciones y censuras, a excepción del Duende de Palacio (1739), periódico manuscrito contra el ministro José Patiño, que ya había estudiado antes: cf. Prensa clandestina española del siglo xuiii: "El Duende Critico", Valladolid, 1968. Según Egido, éste marca un hito en la crítica al gobierno, puesto que en la carga de quejas se incluye por primera vez al Rey. 
ciones sobre imprenta que se dictan en el siglo xvin para frenar el auge de esta literatura prohibida.

Las leyes sobre imprenta se fueron transformando en España debido, a menudo, a fricciones internas. Para acortar una larga historia de tira y aflojas, el Consejo de Castilla otorgaba licencias de impresión desde 1544, decreto que se volvió a aprobar en 1705 , 1728 y $1749^{4}$. Por el Real Decreto de Carlos II antes citado, sabemos que estas disposiciones no se seguían siempre al pie de la letra. Al pagar la tasa de impresión el autor debía depositar algunos ejemplares de su libro; en 1716-1717 Felipe $V$ decide que para evitar excesivos gravámenes, los autores entregarían un ejemplar de sus obras a la Biblioteca Real, a la del Escorial y al Gobernador del Consejo. Este decreto tuvo vigencia hasta 1728, cuando el ministro José Patiño, a causa de un papel anónimo contra su política interior y exterior, ordenó al Consejo que volviese a exigir un tributo mayor de libros. El autor, que antes sólo enviaba ejemplares a las instituciones señaladas, debería ahora depositar cantidades mayores que pagaba de su propio bolsillo (A.H.N., Consejos, 11275). Hacia 1746 el anónimo pero profundo autor de un informe inédito sobre la situación de la imprenta en España denuncia amargamente el resultado de esta dura imposición: "padece la Nación la nota de inaplicada, y atraso en las letras -dice el documentoporque no consigue en el propio [idioma] con que instruirse ya porque no salen a luz obras nuevas, o ya porque no se reimprimen las antiguas" (ibid.). Tres años después, otro decreto prohibía la impresión de todo libro cuyo manuscrito no estuviera autorizado por el Consejo, disposición encaminada a evitar los libelos.

Pese a todos los decretos aludidos, las formalidades sobre impresión "habían quedado en sonido", como dijera el Padre Isla, hasta que Fernando VI instituyó un Juzgado de Imprentas y en 1752 nombró a don Juan Curiel a la cabeza del mismo, donde permaneció hasta $1769^{\circ}$. Curiel tenía prestigiosos antecedentes: en

4 Véanse estos importantes estudios sobre la imprenta y la censura en España: M. Serrano y Sanz, "El Consejo de Castilla y la censura de libros en el siglo xviII", $R A B M, 15$ (1906), 28-46, 242-259, 387-402; 16 (1907), 108116 y 206-218; A. González Palencia, "Joaquín Ibarra y el Juzgado de Imprentas", $R B A M, 3$ (1944), 5-47 [incluido en Eruditos y libreros del siglo xviii, Madrid, 1948, pp. 313-363]; Antonio Sierra Corella, La censura de libros y papeles en España y los indices y catálogos españoles de libros prohibidos, Madrid, 1947. El librito de Francisco Vindel, El Madrid de hace 200 años (1758), Madrid, 1958, es utilísimo; también el de J. E. DE Equizábal, Legislación española sobre imprenta, desde el año 1480 al presente (1873), Madrid, 1879. Las leyes sobre impresiones están fundadas en dos pragmáticas -1502 y 1558-, cf. la Novisima recopilación de 1805 .

s Sobre el tema puede consultarse a Paul J. Guinnard, "Le livre dans la Péninsule Ibérique au xviII siècle. Témoignage d'un libraire français", 
1714 ingresó en la Academia Española, en 1720 obtuvo la Orden de Calatrava, en 1739 figuró como Alcalde de Casa y Corte y en 1745 era miembro del Consejo de Castilla. En 1754 -dos años después de su nombramiento como Juez de Imprentas- ya tenía Curiel ultimadas las nuevas instrucciones sobre impresión y venta de libros en las Españas y su severidad envió a más de un autor e impresor a dar con los huesos en la cárcel o al destierro, además de vaciarles la bolsa, pues tenían que pagar fuertes multas. En resumen, la ley prohibía escribir o reimprimir sin autorización del Consejo, introducir sin permiso libros publicados en el extranjero, ya fueran en romance o en otros idiomas. Si las penas a mercaderes e impresores eran rígidas (más de uno perdió muchos doblones por desacatar órdenes), no menos gravosas lo eran para el propio autor, que debía pagar de su bolsillo a los examinadores nombrados por el Consejo. Cada pliego manuscrito le costaba al escritor dos reales de vellón y un vellón cada folio impreso. Después de muchas discordias y pleitos, esta ley fue revocada finalmente en 1763, con Carlos III ya en el poder.

Según consta en varios oficios manuscritos que se conservan en el Archivo Histórico Nacional de Madrid, Curiel aspiraba a fomentar el desarrollo de la imprenta en España y a frenar la difusión de ideas "subversivas" y de "herejías" que penetraban clandestinamente. Subversión y heterodoxia significaban para la Corona cuanto pudiera resultar en perjuicio de "la Religión, las buenas costumbres, las Regalías de S. M. y el honor de la Nación", según reza la Real Orden aprobada en $1754^{6}$.

Pese a estas férreas medidas siempre se filtraba algo. El 28 de enero de 1756, don Ricardo Wall, irlandés que ocupaba en España el cargo de Primer Secretario de Estado, escribe airado contra Curiel porque, a pesar de su excesivo celo, había permitido pasar El Piscator complutense, de don Francisco de Valdemoros, profesor de teología en Alcalá. Este papel es hoy una rareza bibliográfica y sólo se encuentra entre los legajos de Estado en el Archivo Histórico. En su momento el texto fue a todas vistas escandaloso; se lo incluyó en el İndice inquisitorial de $1756^{`}$. Según R. Wall,

$B H i, 59$ (1957), 176-198, donde reproduce el informe manuscrito del librero francés Antoine Boudet, enviado en 1763 al Juez de Librerías de París, dando cuenta detallada del comercio de libros. Aunque algo al margen del tema que nos ocupa, cf. del mismo autor, La presse espagnole de 1737 à 1751. Formation et signification d'un genre. Paris, 1973. Es imprescindible el libro de A. González Palencia, El sevillano D. Juan Curiel, juez de imprentas, Madrid, 1946 .

6 A.H.N., Consejos, 11275 y 51634, Exp. 1.

7 El título completo es El Piscator complutense y primer teólogo astrólogo. $\mathrm{Su}$ autor $\mathrm{D}$. Francisco Solem, profesor de teologia en la Universidad de 
... son tantas y tantas las suciedades, insolencias y desacatos que se contiene que apenas encontrará en él cláusula que no sea soez, obscena y desvergonzada. Háse escandalizado todo el público de ver que se haya permitido salir a luz un escrito en tales circunstancias; y este escándalo haya llegado también a los oídos del Rey 8 .

La descripción de Wall contrasta por su dureza con la que del mismo Piscator hace el conde de Aranda, entonces embajador en Lisboa, quien observa con ironía en carta al duque de Alba:

Ya tengo el Almanak complutense, muy borrical, y me admiro que los frailes lo aprobasen; pero como las desvergüenzas son propias de la capilla y de los sopistas licenciadones, tomaron a gracia su contenido?.

A raíz del revuelo, Curiel recibió una reprimenda oficial y el autor del malhadado almanaque fue desterrado durante cinco años a veinte leguas de la Corte y de Alcalá. Además se le prohibió terminantemente volver a escribir pronósticos, pecado en el cual, que sepamos, no volvió a reincidir. Pero no sólo padecieron Curiel y Valdemoros - cuyo verdadero nombre era Francisco Martínez Molés Valdemoros, paupérrimo profesor de teología en Alcalá, traductor años después, cuando ocupaba el cargo de Abad de Villafranca, de las Meditaciones sobre el Evangelio de Bossuet (1770-1771) -; como escarmiento también se desterró a veinte leguas de sus conventos a los dos religiosos que aprobaron la obra. Valdemoros consiguió el indulto en 1760 y el decreto autógrafo de Wall lee: "Indultado y que se abstenga de semejantes escritos".

¿Qué novedades ofrecía el Piscator complutense que provocara tamaña reacción de las autoridades? No fue este el primero de Valdemoros; ya en 1755 publicó otro que había pasado totalmente desapercibido. Sin duda, confiado en obtener algunas ganancias, en el segundo extremó su desfachatez. El de 1756 es una imitación bastante servil del lenguaje quevedesco y de Torres Villarroel. Pero lo que desató las iras de Wall fueron los versos francamente desenfadados y libelosos con que el "chofista" ataca algunos ministros, particularmente a Wall mismo, mientras le advierte al Rey

Alcalá. Con lic. En Madrid. En la oficina de Joaquin Ibarra, 1756. Miguel Gómez del Campillo reproduce parte en "El Rey, el Consejo de Castilla, el juez de imprentas y un estudiante chofista (1756)", $R B A M, 15$ (1946), 1756. Los documentos que he consultado figuran en A.H.N., Consejos, 11275 y Estado, 3185, Exp. 2.

8 Consejos, 11275. El memorial de Curiel al Rey es del 23 de octubre de 1756 .

9 Documentos escogidos del Archivo de la Casa de Alba; los publicó la Duquesa de Berwick y de Alba, Condesa de Sỉruela, Madrid, 1891, p. 556. 
que no se fíe de sus consejeros. Sirvan como ejemplo las siguientes alusiones:

Un Capellán, y un Letrado, juntos con un Arbitrista, votarán cierto negocio: mira que Trinca!

O cuando entre las "novedades". de la luna de abril augura en quintillas

En un Tratado secreto entre seis ministros legos; y uno, que era el más despierto, fue quien campó, porque el tuerto es Rey en tierra de ciegos ${ }^{10}$.

Igual que otros piscatores, Valdemoros mezcla con picardía y malicia el caudal de chismografía cortesana, presa magnífica para hacer circular más o menos a socapa las pullas contra los ministros y el gobierno. Las libertades de lenguaje y las cuestiones candentes, aunque tratadas con prisa y desmaño, eran óptimas razones para una venta segura. El descaro y atrevimiento garantizaban cierta remuneración decorosa. La que obtuvo Valdemoros no fue tan exigua, pues en la hoja de balance del librero, Juan de San Martín, de la calle de la Montera consta que se publicaron quinientos ejemplares, de los cuales el autor logró vender trescientos sesenta y cinco, antes que las autoridades los recogieran, con una ganancia de ciento ochenta y dos reales y medio, cifra nada deleznable, pero que evidentemente no compensaría los cinco años de destierro. En la requisa practicada por orden del alcalde de Madrid a través de las librerías situadas en la Plaza de la Cebada, calles de Toledo, Atocha, Montera, Puerta del Sol y gradas de San Felipe, en busca de algún ejemplar, todos los vendedores respondían a las autoridades que "no le hallaría aunque diera un doblón por él". Las mujeres ambulantes que comerciaban en libros declararon que habían vendido algunas docenas y que de quedarles algún ejempiar "había hombre que ofrecía por cada uno cuanto quisieran pedir". La curiosidad y la prohibición eran, por lo visto, incentivos de lectura.

Curiel, que se había visto envuelto en el barullo en torno al Piscalor escribió al Rey una Memoria sobre el asunto, que permite trazar un cuadro bastante preciso sobre los gustos literarios y éxitos editoriales del momento. De este documento resulta evidente que el público español devoraba pronósticos y almanaques, moda que explotó sobre todo el bien conocido Torres Villarroel y que

10 El Piscrtor complutense, pp. 33 y 28 . He modernizado la grafía. 
a imitación suya siguieron otros autores. Los pronósticos que aparecian anualmente eran, al parecer, lectura del pueblo, a quien servian de pasatiempo. En cambio, según Curiel, la gente seria no los leía, a no ser que alguno naciera con revuelo, como ocurrió con el de Valdemoros. El texto de Curiel aclara que el gobierno permitía algunos como incentivo al estudio de las ciencias:

...de estos Piscatores - dice Curiel-salen todos los años muchos, que se consienten y corren examinados antes, porque la juventud con la emulación, o por el interés se active y aplique al estudio de la astronomía, y para que la gente ociosa, o la que ocupada necesite de algún descanso, logren esta diversión o pasatiempo inocente. Tan para éstos solos es la lectura de semejantes Piscatores, y corren tan fuera de comercio de la gente seria, que siendo tantos los Ministros del Consejo ninguno había visto este Complutense, hasta que el haberlo hecho recoger en esta Corte y en Alcalá el 26 del mes pasado ${ }^{11}$.

Este almanaque provocó una mayor severidad en las leyes de imprenta. Curiel le indicó al Rey que a una sola persona le era imposible garantizar cuanto se publicara y era necesario nombrar más examinadores, en lugar de dejarse guiar sólo por las "aprobaciones", como en el caso de Valdemoros. Y, agregaba, puesto que ninguno de los "más condecorados sujetos y literatos de esta Corte" aceptaban censurar libros sin algún tipo de gratificación, al propio autor debiera corresponder pagar la tasa. De esta manera el Juez de Imprentas salvaba su responsabilidad. En adelante el censor sería un asalariado. Aprobada la nueva disposición, en la Introducción que envía Curiel a los censores, exige riguroso examen de las obras y toma otra serie de precauciones. No solo era necesario -como en 1754- estrechar la vigilancia en materias de religión y regalías, también había que pasar por el tamiz las obras "apócrifas, supersticiosas, reprobadas o de cosas vanas, y sin provecho, o si contienen alguna ofensa a la Comunidad, o a Particular, o en agravio del honor, y decoro de la Nación" ${ }^{12}$. La maliciosa sombra del Piscator complutense se hace sentir en la censura de libros.

Gracias a la redoblada escrupulosidad de Curiel podemos contar hoy con testimonios sobre diversos tipos de impresiones. En ese mismo año de 1756 se registra otro caso singular que corrobora la acepción legal del vocablo clandestino hasta abarcar el contenido ideológico. En enero, el corregidor de Salamanca informaba sobre diligencias practicadas para descubrir al autor e impresor de dos hojas en cuartilla tituladas Noticias del Paraguay de Nicolao I.

11 A.H.N., Consejos, 11275 , fechada el 2 de febrezo de 1756 , ff. $5-6$.

12 A.H.N., Consejos, 51634, Exp. 1, p. 2. 
incautadas a la mujer de un ciego que las vendía públicamente en esa ciudad (A.H.N., Consejos, 11275). El papel no era otra cosa que la versión española de la Gaceta de Holanda, donde se daba noticia de los percances ocurridos entre un misionero jesuíta que fue al Paraguay y una tribu indígena, en torno a problemas de términos de posesiones. De esto se hizo novela y se empezó a hablar del reino de Nicolao, que hasta acuñaba moneda ${ }^{13}$.

En España la reacción del monarca fue dura. ¿Qué provocarít las iras de Fernando VI? Las fabulaciones sobre América habían sido alimento de hiperbólicas descripciones en los siglos xvr y xvu. Sin embargo, en este caso el Rey ordenó una rigurosa investigación con instrucciones precisas de que "esto se ejecute con toda eficacia, diligencia y secreto". A cuantos se les tomó testimonio se les advirtió "que si revelaren estas reservadas diligencias, se tomará con ellos la más severa providencia" 14 . Fernando VI encargó al obispo de Cartagena, don Diego de Rojas y Contreras, miembro del Consejo de Castilla, las averiguaciones pertinentes, y éste instituyó un auto. De acuerdo con la documentación conservada, en la Península se habían esparcido rumores acerca de las cosas del Paraguay y como no había ningún papel oficial impreso - explica el Corregidor- el público se vio "en precisión de mendigar a los extranjeros" para enterarse. (Por cierto el Corregidor cita del papel impreso en Salamanca. El párrafo inicial coincide casi palabra por palabra con el informe del obispo. Sin duda, el hecho de que se expresara con tanta claridad que España no daba noticias sobre el asunto y que, por tanto, había que mendigarlas al extranjero, debe haber influido notablemente en la prohibición del papel). De la historia verdadera se creó la novela ficticia del Rey Nico. lao. Al final del memorial, el obispo añade en tono proverbial "a luengas tierras, luengas mentiras" (ibid.). Finalmente se puso en libertad al impresor salmantino. Pero, ¿por qué el sigilo y el cuidado? No parece que se debiera exclusivamente al hecho

13 Véase ahora Historia de Nicolés I, Rey del Paraguay y emperador de los mamelucos, introd. de S. Buarque de Holanda, Universidad de Chile, 1964. Esta versión en español llevaba como pie de imprenta "A St. Paul, 1756", y dista mucho de la más corta impresa en Salamanca por José de Villagordo. Este episodio ha suscitado varios estudios; véase entre otros EFraív Cardoso, Historiografía paraguaya, México, 1959, t. 1, pp. 381-382; Magnus Mörner, The expulsion of the jesuits from Latin America, New York, 1965, y sobre todo, Richard Konetzke, América Latina. La época colonial, MéxicoMadrid, 1972, p. 258, sugiere que esta leyenda se debió probablemente a la pluma del ministro portugués Pombal o se redactó por su iniciativa. En todo caso la presunta "biografía" del ex jesuita, el rey Nicolás I, fue muy bien acogida por los adversarios de la Compañía en Europa. Obsérvese como dista de la realidad la versión difundida en Europa, que aquí nos ocupa.

14 Consejos, 11275, carta del 18 de febrero de 1756 . 
de que el pliego estuviera publicado sin los requisitos legales. Según el texto incautado a la mujer del ciego salmantino, el fabulado título de Rey Nicolao se le concedió a un jesuita. Esta leyenda de un ex jesuíta, presunto rey de un país americano, adquirió amplia difusión $y$, en la versión impresa en Salamanca, el jesuíta, que había fundado un estado propio en el corazón de la selva, no había logrado apaciguar a los guaranies rebeldes. El fracaso en lejanas tierras de un misionero adelantado sirvió de entretenimiento al público sediento de lances y aventuras, pero dejaba malparada la reputación de la orgullosa Orden de San Ignacio.

La investigación histórica ha demostrado la falsedad de esa leyenda. El episodio verdadero fue un problema de límites entre España y Portugal. El Tratado de Madrid de 1750 había estipulado que Portugal renunciaría a la colonia de Sacramento, a la margen izquierda del Río de la Plata y recibiría en cambio el territorio ocupado por siete pueblos de las misiones jesuíticas del Paraguay. A la Compañía, claro está, no le gustó el arreglo; tampoco a los indígenas que se negaron a abandonar las tierras y se levantaron en armas. En 1754, cuando se lidió la primera batalla, los indios triunfaron, pero en 1756 los ejércitos combinados de España y Portugal vencieron a los rebeldes. El cabecilla de la rebelión -José Tiarayé, conocido por el sobrenombre de Sepé- murió en la lucha, y fue prácticamente canonizado como el Santo Sepé. Otro cabecilla, Nicolás Neeguirá, corregidor del pueblo de La Concepción fue el designado con el ampuloso título de "Rey del Paraguay". Con estos acontecimientos reales la Europa antijesuítica urdió una fantasía novelesca.

El incidente repercutió más allá de las fronteras españolas. Los gacetilleros de Europa difundieron la leyenda y el episodio fue pasto de innumerables novelas vertidas al francés, italiano, alemán. Unos la llamaron "guerra guaranítica"; Voltaire evocó el suceso en Candide y en Essai sur les moeurs. En el primero acepta la versión de un jesuíta que reinaba en Paraguay, y en su Essai retoma el hilo y aduce que la provincia de San Nicolás se había sublevado bajo las órdenes de los jesuítas y uno de ellos se había proclamado rey. Ya sabemos que ninguna de estas versiones literarias corresponde a la realidad, y que, por lo visto, los jesuítas estuvieron realmente implicados en la rebelión. Consta que se encarceló a los padres Tadeo Ennis y Francisco Lamp (ambos mencionados por Voltaire), a quienes se acusó de fomentar las iras de los guaraníes ${ }^{15}$. En su época no faltó quién achacara la confección de la trama novelesca a los enemigos de la Compañía de Jesús; otros, en cam-

15 Konetzke, op. cit. pp. 256-258, opina que los jesuitas estaban mezclados en el asunto. 
bio, atribuyen la historia a algún jesuita salmantino, ya que en esa ciudad se imprimió la incautada, muy distinta, por cierto, de la traducida luego a varios idiomas. Por lo que concierne al Tratado de Límites, recuérdese que dos años después se interpretó el Fray Gerundio como venganza de un jesuíta refractario al acuerdo, hecho que influyó no poco en la prohibición de la novela del padre Isla.

Prosigamos con otros papeles prohibidos. Conocido personaje de los romances de ciegos es "El Patán de Carabanchel", nombre que en el siglo xvin sirve de pseudónimo para escudar a diversos osados. En 1746 parece haberlo adoptado el agente de negocios Francisco Maíz, que fue a parar a la cárcel con los ciegos vendedores por publicar un pliego de cordel clandestino sin las licencias necesarias y, sobre todo, por ser "escandaloso", según reza el auto de oficio ${ }^{16}$. Este romance refleja el grado de crítica política y social del setecientos, que incorpora toda la retahila de quejas ya elaboradas desde el xvn por "repúblicos" y arbitristas. Los juicios contra el país son múltiples: el comercio languidece, los telares y la industria están paralizados, se descuidan las Indias, los ministros son venales. El "Patán", en nombre del pueblo, pide al Rey reformas en todos los ramos; sólo el monarca podrá salvar del caos y la crisis al pueblo confiado. El papelito - del cual se tiraron unos cuatro mil ejemplares- debió circular bastante, pues aún se encuentra en diversas bibliotecas del mundo. Otro tanto ocurrió con las coplas tituladas Expresión filial...[de] un Amante aragonés, impresa por José Font con licencia en Zaragoza en 1746. El texto ofrece idéntico haz de quejas.

Las extensas pesquisas llevadas a cabo para identificar a los autores e impresores de estos papeles nos permitirán esbozar un cuadro sobre algunos aspectos de la censura civil española. El juez privativo de la Comisión de Impresiones informó que ambos se vendían públicamente por los ciegos. Al día siguiente de la delación -26 de septiembre de 1746- el alguacil prendió a un ciego y recogió seis ejemplares del Patán y ochenta y cuatro de la Expresión filial. Al tomársele declaración, el ciego confesó que hallándose en Valladolid recibió un impreso del Patán, del cual mandó tirar a su costa dos resmas. Fue luego a Madrid, donde vendió algunos a otros ciegos y se quedó con el resto. De la Expresión filial, en cambio, compró varios ejemplares a otro miembro de la Hermandad, en San Felipe Real. No satisfecho con estas aclaraciones, el alguacil interrogó a otro ciego, especializado en la venta de gacetas, y así nos enteramos que él se había negado a vender ambos pliegos "por haber oído que se había privado su venta". 
Evidentemente las noticias cundían con rapidez. Entre delación y delación, pronto el escribano y alguacil fueron a dar con Francisco Maíz, que el 28 de ese mes juraba que había pedido licencia para imprimir el Patán y se le había otorgado. Ya impreso, lo vendía la librería de Alfonso Vindel, hasta que se mandó recoger. El mismo impresor, Domingo Fernández de Arrojo, fue preso por imprimir Expresión filial, acusación que rechazó ${ }^{17}$. Nada más sabemos sobre la suerte de Maíz, los ciegos y el impresor, pero estos conflictos entre impresores, vendedores ambulantes y libreros nos permiten reconstruir algo de esa historia medio oscura de la literatura popular semi-clandestina. Las musas se despertaban en ella para celebrar las misceláneas y casos del momento, no sin cierto riesgo.

Estos dos romances distan mucho de los ejemplos de literatura popular a que aludimos antes aunque, como ellos, fueron prohibidos. A diferencia del papel sobre el Paraguay, por ejemplo, donde se fabulan historias verdaderas, otros romances son representativos de una literatura de protesta social vertida en metros populares y vendida por los ciegos. Coinciden en esto con el Piscator complutense y como él, aluden a circunstancias políticas del momento. Pero, tanto el Patán como el Amante aragonés centran su crítica en aspectos sociales y económicos.

La literatura clandestina y semi-clandestina del setecientos, pues, puede dividirse en aquélla de orden político donde un autor, en general encubierto bajo un nombre genérico - Juan del Pueblo, El amante del bien, El Patán de Carabanchel, Perico y Maricaincita a una acción política eficaz y se identifica con las quejas del pueblo, mientras denuncia los errores de los gobernantes; y aquella otra, publicada sin los requisitos legales necesarios, pero desprovista de contenido político. Según la primera, el mal gobierno multiplica contribuciones y carga de pensiones y sobresueldos a los ministros aduladores dilapidando así los escasos recursos del país. La letanía de cargos suele ser extensa, cubre todas las ramas de la política y expone con claridad el haz de rencores y descontento populares ${ }^{18}$. Frente a estos textos que reflejan el surgimiento de la oposición pública, está ese otro tipo de producción literaria que permite entrever los temas que consumía el público peninsular durante la primera mitad del siglo xvirI y estudiar sus gustos e intereses literarios. El gobierno de Carlos III (1759-1788) se caracterizará por su esfuerzo en abolir de raíz estas expresiones artísticas clandestinas y su aspiración a transformar los hábitos de lectura del pueblo.

17 Abrevio aqui la información que se encuentra en A.H.N., ibid.

18 Trabajo este tema en un libro próximo a publicarse por Ariel, Barcelona: Clandestinidad y libertinaje erudito en los albores del siglo xiriii. 
Con Carlos III y Carlos IV la censura de libros no parece haber sido menos rígida que la de sus antecesores en lo que concierne a la literatura de cordel, blanco de las críticas de sus ministros. Entre 1760 y 1766 hubo gran actividad y celo; por entonces se les incautan y recogen diversos impresos a varios autores y libreros del reino. Creo que la documentación inédita que he logrado manejar me permitirá esbozar algunas ideas sobre los distintos tipos de literatura en clandestinidad durante los últimos años de! siglo.

Es bien sabido que el Fray Gerundio de Isla tuvo problemas y que en 1760 la primera parte fue prohibida por la Inquisición debido a presiones eclesiásticas. Un mes después de su aparición, en marzo de 1758, Curiel envió un extenso expediente sobre Isla a los jueces de imprenta del reino con orden de que no se permitiera o imprimiera "papel alguno por corto que sea en pro, o en contra de la historia de Fray Gerundio" (A.H.N., Consejos, 56080) . Añade que el Consejo había otorgado ya licencia para el segundo volumen; pero éste no apareció hasta 1770 , ya que los lectores descontentos ahogaron en quejas a la Inquisición. La orden de Curiel fue remitida en 1758 a Sevilla, Córdoba, Jaén, Coruña, Santiago, Málaga, Bilbao, Cervera, Orihuela, Granada, extensa lista de ciudades que permite trazar una geografía de la imprenta. Que sepamos, de todos los subdelegados, solo el de Granada respondió que tal vez no podría evitar las publicaciones polémicas contra Isla, en vista de que los trinitarios tenían imprenta en su convento $y$, añade, "mayormente siendo la obra de la naturaleza que es, es natural que no haya sentado bien a los regulares" (ibid., carta del 14 de marzo de 1758).

Razón no le faltaba al juez de Granada; por Bernard Gaudeau sabemos que una de las órdenes religiosas más agraviadas fue ésa, aunque otras también polemizaron agriamente con el novelista. Pese a las precauciones de Curiel, muchos de estos escritos circularon, e incluso el propio Isla publicó algunos de ellos. Precisamente fueron estos ataques los que más contribuyeron al éxito editorial de la novela: de los mil quinientos ejemplares impresos se vendieron ochocientos en las primeras veinticuatro horas, y en Valencia hubo quien estaba dispuesto a pagar cien doblones para alquilar una posta que le trajera desde Madrid la segunda parte en cuanto se imprimiera. Isla cuenta con exagerada soberbia en sus Cartas familiares que no había pueblo que desconociera su Fray Gerundio, y que en poco tiempo su fama llegó a París. Él mismo vaticinó el sonado triunfo, pues en la citadísima carta a su cuñado (7 de marzo de 1755) dice: "el ruido y alboroto de los interesados 
(que son innumerables) eternizará mi nombre"; juicio que repite en El circunloquio del Padre José Francisco de Isla, con no poca picardía ${ }^{19}$. ¿Qué ironía que fuera Curiel mismo quien interviniera en la prohibición de la obra! En carta a su cuñado del 18 de noviembre de 1757 , Isla alaba el cuidado que Curiel se tomaba para reprimir la desenfrenada licencia con que se imprimía tanta "bazofia" en España. La segunda parte del Fray Gerundio -escribe- lo convencerá de que ni siquiera su severidad es suficiente "pues todavía se desliza tal cual impreso en mucho descrédito de la Nación" (op. cit., p. 417). Tanto el libro de Isla como el libeloso pronóstico de Valdemoros nos confirman que cuando la censura civil y eclesiástica prohibían algún libro, éste se convertía en lo que hoy podríamos llamar un best-seller.

Por lo visto, si en la Corte el Juez de Imprentas lograba mayor restricción de impresores y mercaderes, en provincia esto era algo más difícil. En los pueblos y ciudades a los que Curiel envió órdenes sobre el Fray Gerundio habia imprentas cuyas actividades no siempre era fácil restringir. El juez subdelegado de Málaga se lamentaba en carta a Curiel del 20 de marzo de 1761 de que los impresores de esa ciudad, cuatro según estadísticas de 1757 (A.H.N., Consejos, 50692), le rogaban a menudo que no censurara las "obrillas" que publicaban, pues sin ellas les sería imposible subsistir. Como resultado, los autores "con la decidia y detención, se pasan a otros pueblos”. Preocupado, el subdelegado de Málaga le explica a Curiel que los dueños de imprenta acudían con frecuencia para obtener permiso de impresión precisamente de esa literatura popular que tanto molestaba a los ilustrados. Según el juez malagueño, los impresores iban con "coplas narrando hechos que no han sucedido, y entretejiendo mil disparates sólo con la idea de dar de comer a los ciegos, y trabajar en sus imprentas". Y, añade, que él muchas veces se había negado a otorgar permiso, consciente de que esta literatura sirve "más de impertinencia que de provecho al público". Según el juez, las coplas de ciegos instan a que "la mujer tome ejemplo, e ideas para ser desleal al marido, al hijo, o al criado de robar al padre, o al amo, y el reo de hacerse más insolente, y resistir a la justicia" ${ }^{20}$. Pero, además de las razones morales y utilitarias que trascienden los informes del juez de Málaga, lo que sí queda claro es que esa literatura gozaba gran popularidad entre el pueblo.

Mucho molestaría a los ministros de Carlos III este género de literatura, pues en 1767 el Rey proclamó un bando prohibiendo

19 Obras escogidas, BAE, t. 15, pp. $469,474$.

20 Consejos, 50688; con fecha del 16 de enero de 1760 firman dos im. presores. 
que se concedieran licencias para imprimirla. Estos textos -prosigue el bando- son

...perjudiciales al público, además de ser lectura vana, y de ninguna utilidad a la pública instrucción, pudiendo dedicarse las personas de talento a escribir cosas provechosas, y que fomenten la educación, el comercio, las artes, la agricultura y todos los descubrimientos.

Es muy probable que Pedro de Campomanes fuera uno de los inspiradores de este decreto, pues al entrar en la Fiscalía del Consejo en 1766, confesaba en carta a Manuel de Roda que uno de sus propósitos era "detener la barbarie que nos amenaza en medio de la ilustración de nuestros vecinos" 21. El mejoramiento de las letras -es decir, la cultura dirigida- formaba ya entonces parte sustancial de la política de los ilustrados españoles.

Pero en España Campomanes no se limitaba a perorar contra la mala literatura, sino que llega a intervenir muy directamente en su censura. En 1766 mandó a recoger un piscator, esta vez de Bartolomé Ulloa, por contener "particulares referentes a materias de gobierno impropios de la naturaleza de esa obra, y por perjudiciales al público" $\cdots 2$. Ese mismo año mandó expurgar un pronóstico de Torres Villarroel y otro de su sobrino, Isidro Ortiz Gallardo, titulados La tía y la sobrina y La embajada de los astros respectivamente. Ambos, según el oficio, "anuncian diferentes sucesos políticos, en forma de adivinanzas, que pueden traer siniestra interpretación; y [ser] su leyenda perjudicial al público". Tanto el pronóstico de Ulloa, como los de Torres y Ortiz Gallardo, se podrían reimprimir

...con la prevención de que en los calendarios nada se toque de gobierno, ni de sucesos políticos, poniéndose en el prólogo la carta escrita por el Dr. Isidro Ortiz Gallardo [...] y que lo mismo se ejecute con el de Ulloa [...]. Ya enmendados que se proceda a la venta (ibid.).

No he logrado cotejar estos textos, pues no figuran en los expedientes, pero no sería improbable que los tres piscatores aludieran al Motín de Esquilache, que estalló en Madrid en 1766 y pronto se extendió por todo el país. La conjetura no me parece muy desacertada, ya que la Inquisición prohibió todos los papeles, coplas y libelos que con motivo del Motín se difundieron dentro

2I Apud Francisco Aguilar Piñal en la introd. a Manuel Lanz de CasaFONDA, Diálogos de Chindulza, Cátedra Feijoo, Univ. de Oviedo, 1972, p. 196, nota 102. 1766 .

22 A.H.N., 50695, carta de J. de Peñuelas a Curiel, 25 de noviembre de 
y fuera de la Corte. Años después, con idéntico espíritu, se prohibieron los papeles, estampas y sátiras divulgados contra la conducta del Rey y sus ministros en la expulsión de los jesuitas en 1787 .

En 1766 no sólo se incautaron y expurgaron piscatores; ese mismo año Curiel hizo registro de librerías y de los puestos públicos del reino, en los que encontró buen número de libros prohibidos (A.H.N., Consejos, 50693). La lista de las obras recogidas en Sevilla, Santiago y Toledo, nos descubre que predominan las "historias", relaciones en prosa y verso, a menudo meras descripciones de sucesos, que desde los siglos xv y xvi satisfacían el público afán de novedades. Estas "historias" a las cuales aludiremos ahora, así como ciertos libros de oración, también fueron el objetivo de la crítica de los ilustrados.

Uno de los textos más nítidos respecto a los problemas culturales de las postrimerías del siglo xvin es el Discurso sobre la educación popular de los artesanos y su fomento (Madrid, 1775), de Rodríguez Campomanes. En él, pide que se proscriban ciertos romances, que al parecer eran lectura cotidiana en las escuelas del reino:

No deberán leerse en las escuelas romances de ajusticiados -manda Campomanes- porque producen en los rudos semilla de delinquir y de hacerse ladrones. El mismo daño traen los romances de los Doce Pares y otras leyendas vanas o caprichosas (t. 1, p. 153).

Pero, no es éste el único texto contra la literatura popular. Si en 1756 Fernando VI había permitido los pronósticos como incentivo para el estudio de las ciencias entre la juventud -según explicó Curiel en su informe sobre el Piscator complutense-, Carlos III y sus ministros, en cambio, sostienen otras ideas. Quizá no se encuentre juicio más recio, aunque tardío, que el emitido por Juan Meléndez Valdés ante la Sala Primera de Alcaldes de Corte, en 1798. Pide allí la proscripción de romances groseros e inmorales, que pervierten a la juventud ${ }^{23}$. Meléndez no se limitó a nombrar los "romances groseros"; en caudaloso vuelo enumera otros títulos: "el disparatado Carlomagno, La cueva de San Patricio, El espejo de cristal fino, el Belarmino". Veamos de qué tratan algunas de estas obras que Meléndez Valdés en extraño contrapunto, califica

23 El texto íntegro lo reproduce A. González Palencia, Meléndez Valdés y la literatura de cordel, Madrid, 1931. Cito por la versión ampliada incluida en Discursos forenses, Madrid, 1821, pp. 178, 190-191. La intervención de Batilo tuvo lugar durante el ministerio de Godoy, que apoyaba con entusiasmo todo intento de mejorar la enseñanza. Ese mismo año de 1798, un corresponsal anónimo del Diario de Madrid (23 de diciembre), clamaba contra el romance "La despedida de un anciano". Las canciones obscenas a que alude Meléndez fueron reproducidas por González Palencia. 
de obscenas y disparatadas, mientras mezcla "historias" con libros de rezo.

El Espejo de cristal fino, cuya primera edición data de 1625 y se reimprimió muchas veces a lo largo del siglo xviII, es de Pedro de Espinosa, buen amigo de Quevedo, autor también de la conocida antología Flores de poetas ilustres de España (1605), y del tratado ascético Antorcha que aviva el alma. Las obras de Espinosa están dentro de la más rigurosa ortodoxia. Curioso es que Meléndez repruebe tan enérgicamente el Espejo..., pues años antes, el 22 de marzo de 1763, Ricardo Wall, ministro de Estado y de Guerra, lo recomendaba calurosamente al Obispo General del Consejo como "indispensable para la instrucción del pueblo" (A.H.N., Consejos, 5528, núm. 11), con el Catón cristiano del padre Jerónimo Rosales, y el famoso catecismo del Padre Astete, obras estas de enorme popularidad que a menudo tenían tiradas de cuarenta mil ejemplares. Otra lista inédita de libros recomendados hacia la misma fecha, los ve como la piedra angular de la educación del pueblo, igual que a los clásicos Cicerón, Virgilio, Antonio de Nebrija y las fábulas de Esopo (A.H.N., Consejos, 11275) . Fuente de espiritualidad cristiana es también Belarmino, explicación de la doctrina cristiana, de innumerables reimpresiones desde el siglo xvn, pero que Meléndez califica de disparatado en 1798. Los Doce pares no es otro que La historia del emperador Carlomagno y de los doce pares de Francia, cuya primera edición aparece en Sevilla en 1525, y disfraza el Fierabrás francés que Menéndez y Pelayo ${ }^{24}$ observó como recreación del pueblo en todos los rincones de la Penínsuia desde los umbrales del siglo xvi.

Muchas de estas "historias" eran leyendas francesas refundidas y remozadas por autores o libreros anónimos. En Francia formaban parte de la Bibliothèque bleue de Troyes o librería popular ${ }^{25}$. El punto final de la lista de Meléndez, La cueva de San Patricio, proviene del Tractatus de Purgatorio Sancti Patricii, hagiografía caballeresca de 1189, que se difundió en España bajo el título inicial de El Purgatorio de San Patricio desde el siglo xIv, gracias a la traducción de Ramón de Perellós. Muchas mutaciones sufrió la leyenda, pero todavía en el siglo xviri alimentaba el espíritu caballeresco de los españoles ${ }^{20}$.

24 Origenes de la novela, $2^{*}$ ed., Madrid, 1957, t. 1, pp. 218-219.

25 Véase Robert Mandrou, De la culture populaire aux $17^{e}$ et $18^{e}$ siècles. La Bibliothèque bleue de Troyes, Paris, 1964.

26 Debo estos datos a la generosa amabilidad de la profesora Sylvia Roubaud, que me indicó textos y bibliografía. Cf. A. G. Solalinde, "La primera versión española de El Purgatorio de San Patricio y la difusión de esta leyenda en España", Homenaje a Ramón Menéndez Pidal, Madrid, 1925, t. 2, pp. $219-257$. 
Si la enumeración de Meléndez Valdés nos proporciona una mina de detalles preciosos para el estudio de los gustos populares, no menos sabor tiene el cargamento de "historias" que vendía un ciego forastero de feria en feria en esas postrimerías del siglo xviII. En su posesión traía Carlomagno, Roberto el Diablo, Oliveros, Francisco Esteban, San Alejo, San Anaro, Bernardo el Carpio, El conde Partinuplés, Los siete infantes de Lara. El documento de registro firmado por el mismo ciego permite deducir que otros miembros de la Hermandad llevarían títulos parecidos (A.H.N., Consejos, 11275). Estas misceláneas aparecieron en los puestos y librerías del Reino cuando Curiel realizó el registro de 1766, además de las "historias" de Flores y Blancaflor, Clamandes y Claramonda y Pierres y la linda Magalona.

Hagamos el escrutinio de esta librería andante. Las dos últimas "historias" son traducciones del francés: Clamandes y Claramonda se editó por vez primera en Burgos en 1480, coincidiendo así con la primera edición de Lyon ${ }^{2 \tau}$. La fuente común es el poema Cleomades, del poeta Adenet le Roi y, al parecer, influyó en el episodio de Clavileño del Quijote. Pierres... también se remonta a la segunda mitad del siglo xv (Lyon, 1478), con primera edición española en Sevilla, 1519. La historia de los dos enamorados Flores y Blancaflor era bien conocida en Castilla desde los albores del siglo xiv y admirada por Juan Ruiz, que la elogia en el Libro de buen amor ${ }^{28}$. La historia de las penas y quebrantos de estos enamorados -él moro, ella cristiana- brota de dos poemas franceses medievales, y tiene una versión aristocrática y otra popular. Esta última, por lo visto, se recitaba entre los peregrinos que iban a Santiago, y el texto en prosa ejerció notable influencia en los romances de El conde Flores. En todo caso, estas obritas se imprimieron como literatura de cordel en forma abreviadísima, pues muchas veces sólo se entresacaba un episodio de la fábula. Como testimonio de quien las leía, es sugestiva la irónica alusión del Padre Isla sobre aquel labrador de Salamanca cuya única fuente de cultura eran El Catón cristiano y los Doce pares ${ }^{29}$. Religión y caballería aparecen allí en estrecha alianza.

-7 Menéndez Pelayo, op. cit., t. 1, p. 237, y la ed. de A. Bonilla de San Martín, 1916.

28 Los versos del Arcipreste dicen: "Ca nunca fue tan leal nin Blanca Flor á Flores / nin es agora Tristán á todos sus amores..." (ed. de J. Cejador Frauca, Clás. cast., p. 283).

29 Cf. Cartas de Juan de la Encina, BAE, p. 417. Jovellanos (Diarios, BAE, t. 85 , p. $304 a$ ) hace el recuento de la librería de un vecino acomodado de La Pola de Gordón y anota un misal viejo, una vida de la Virgen, devocio. narios, un lunario, un libro de reducción de monedas. Evidentemente el propietario se preocupaba por la salud del alma y además de las estaciones, con el propósito de predecir las cosechas. 
Es sugestivo el cargamento del ciego viajero, que coincide con la mercancía requisada en las librerías del reino, así como con el panorama que pintan Meléndez Valdés y Campomanes. Batila amplía sus observaciones en los Discursos forenses (1821), y reanuda su ataque a los romances perniciosos que "llenan los puestos y tendidos de esta nobilísima Corte, de los pueblos y ferias de todo el Reino" (pp. 170-171). El abanico de temas incluye vidas de santos, hagiografías simples, donde los milagros saltan a cada página. Son tesis religiosas tradicionales (San Alejo el anacoreta, San Albano, San Anaro, Santa Genoveva). En otros casos, vidas de paladines y grandes héroes (Bernardo del Carpio), novelitas caballerescas como Roberto el Diablo o bien vidas de condenados y de bandoleros. El Partinuplés representa el espíritu guerrero y ruda de la Edad Media; Roberto el Diablo es maral y ascética en el fondo. Son novelitas algo disparatadas, que subsistieron pese a las eruditas denuncias de Luis Vives, Malón de Chaide, Aleja de Venegas y fray Luis de León, entre otros. Tampoco las burlas de Quevedo y Cervantes produjeron el efecto deseado, pues todavía siglo y medio después el pueblo se deleitaba con esas ficciones que seguían reimprimiendo impresores y editores. Hasta tal punto pervivieron que ya entrado el siglo xix la Librería y Casa Editorial Hernando de Madrid publicó muchas de ellas.

Alguna explota los prejuicios populares. Natural es que Roberto el Diablo, en su penitencia, fustigue a los judíos con el beneplácito del Papa. Se atacan las otras religiones y se defienden los valores de la religión católica. La bella historia amorosa de Flores y Blancaflor se ve ensombrecida por el origen árabe del enamorado y Dios mismo, convierte a Flores a "los mandamientos de Dios y de la Santa Madre Iglesia”, por intercesión de la bella cristiana.

Como los almanaques, pronósticos y romances de ciego, estas "historias" están impresas en papel malo y mal cortado. No es improbable que esta literatura estuviera destinada a la lectura en alta voz, puesto que el analfabetismo impedía otro medio de comunicación que no fuera el oral. En los pueblos recónditos, el ciego, buhonero o librero ambulante pasaba dos o tres veces al año. La feria era el suceso cultural más importante; durante el resto del tiempo los habitantes sólo se alimentaban de los sermones dominicales -que tan certeramente ridiculiza Isla- y de la lectura de ordenanzas reales. En las grandes ciudades la situación era algo distinta, pues cabía la posibilidad de otros medios de entretenimiento: periódicos, afiches, libelos pasados de mano en mano en mercados y ferias o pegados en los pórticos de las iglesias y en los muros de la ciudad. Además, había proclamas casi diarias de las autoridades municipales, más teatros y otras diversiones. 
Lo cierto es que aun sin salir del terreno de datos ya conocidos, tanto en la gran ciudad como en el campo, la literatura de cordel y los papeles vendidos por los ciegos eran presa cultural de la España del Antiguo Régimen. El derroche de ingenio, a veces chocarrero y disparatado de los poetastros a sueldo de ciegos fue magnífico blanco de la sátira de humanistas y escritores cultos por lo menos desde el Siglo de Oro. En El Buscón (Lib. II, ed. Lázaro Carreter, Madrid, 1965), Pablos emprende camino hacia Madrid y se encuentra con un poeta a quien niños y ciegos reconocen por la voz y hasta por el olor. Más de doce ciegos se le arremolinaron en torno y comenzaron a pedirle oraciones para el Justo Juez, pero escritas "en verso grave y sonoro, tal que provocase a gestos". También le encargaron nuevos rezos de las ánimas. Al final, el poeta recibió ocho reales de señal de cada ciego, ganancia nada deleznable, desde luego. Hostil al ingenio fácil, Quevedo la emprende contra "este género de sabandijas" (p. 114). En los Sueños remacha su disgusto en caricaturas aún más estilizadas. Poetas, ciegos y arbitristas eran el azote de los escritores cultos.

Por irónica coincidencia, Erasmo habría de hacer uso de los ciegos italianos para poder dar a conocer su librillo Conclusiones principaliter suspectae et scandalosae quae reperiuntur in libris Erasmi (Roma, 1522) que de otra forma no se hubiera conocido. Solo estos arriesgados mercaderes, llamados por algunos bancarellari ${ }^{30}$, osaban contravenir la censura; pero, el humanista no esconde su juicio tajante y con desprecio explica que sólo se atrevieron a vender su libro "esos rapaces ambulantes que van por Roma pregonando huevos, hongos, almanaques, cancioncillas y otras bagatelas semejantes" ${ }^{31}$. Para continuar los remolinos de censura contra estos personajes, conocido es el papel que desempeñó el impresor Miguel de Eguía en el humanismo español. Temperaments activo e ingenioso, escribía hacia 1525 al arzobispo Fonseca que "los talleres tipográficos de España están acaparados permanentemente por coplas vulgares y hasta obscenas, por versos ineptos o por libros de menos valor aún". Los doctos esperan los libros -dice- "como riquezas de Indias" (ibid., p. 163). El eco de sus palabras se percibe en la firme delación de Meléndez Valdés tres siglos después.

30 Así los llama el comunista italiano Antonio Gramsci y, según él, estos vendedores ambulantes provenían de la Toscana, cf. Cultura y literatura, sel. y prólogo de J. Solé-Tura, Barcelona, 1972, p. 257. Además del libro de MANDrou (cf. supra, nota 26) véase Geneviève BollèMe, "Littérature populaire et littérature de colportage au $18^{\mathrm{e}}$ siècle", Lizre et société dans la France du xuizie siècle, Paris, 1965, t. 1, pp. 61-92, excelente análisis de este mundo en Francia.

31. Marcel Batallon, Erasino y Españu, México, 1966, p. 131. 
$\mathrm{Si}$ en las grandes ciudades ciegos y literatura de cordel se explayaban con relativa libertad, en las aldeas y villorrios eran los heraldos casi oficiales de noticias. ¿Es necesario recordar la vida triste y sórdida de tanto pueblo en la España del Antiguo Régimen? Hacia 1727-1728, Torres Villarroel la pinta en sus Visiones y visitas como misérrima y, lo que es más, agrega: "Los caudales de las villas, aldeas y ciudades, todos vienen en recuas a la Corte. Aquí todo se consume, y allá quedan consumidos" 32 . Corte y provincias contrastan también en las descripciones de Tomás de Iriarte, quien en 1781 le contaba a su amigo Manuel Manca el desprecio que por la pluma sentían los pueblerinos. Sus confidencias nos permiten recrear las actividades del pueblo, donde los ciegos cantan en "jácaras malditas" las noches de Semana Santa. Desde su retiro en Gascuña, pueblo de Cuenca, es aún más específico respecto a la prensa y expresa su enojo en versos satíricos:

Aquí ninguno sabe ni averigua

si en España hay o no literatura;

y fuera poco menos que locura

tratar de erudición nueva o antigua.

Aquí tan solo la Gaceta leen,

y en tanto que la escuchan no respiran;

reverentes la creen

y hasta su estilo castellano admiran ${ }^{33}$.

El poema revela que el pueblo se nutría de noticias leídas en alta voz, costumbre que insinúa el prólogo de Nicolás de Piamonte a la edición de 1695 de La historia del Emperador Carlomagno, al suplicar "a cualquiera que lo leyere, o oyere [...] no mire el error de la pluma". Tampoco hay que olvidar que cuentan los cronistas que el matemático Torres Villarroel se paseaba por las galerías del Palacio de Monterrey, en Salamanca, lanzando predicciones meteorológicas a los labradores y a las multitudes que lo escuchaban arrobados.

He sintetizado en estas páginas la variada gama de literatura popular - semi-clandestina y clandestina- que ve la luz a lo largo del siglo xvin. Ella nos sirve a menudo para pulsar los ánimos del pueblo, sus reacciones ante el gobierno y ante el propio monarca. En algunos momentos transcribe directamente el malestar general ante las estrecheces económicas y las crisis; en otros, recoge las

32 Visiones y visitas de Torres con don Francisco de Quevedo por la Corte, ed., introd. y notas de R. P. Sebold, Madrid, 1966, p. 192. (Clás. cast.).

83 Apud E. Cotarelo Mori, Iriarte y su época, Madrid, 1897, pp. 473-475. 
habladurías que corren en torno a los principales personajes de la Corte.

Además de esa literatura de tema social, he señalado otro, cuyo éxito nos ha permitido esbozar un cuadro de lo que se leía en España para esparcimiento y recreo. Pese a los redoblados esfuerzos de humanistas e ilustrados, el público no siempre leía para esmerarse y cultivar su inteligencia. Más bien prefería evocar lo que no pertenecía a su mundo cotidiano: mitología histórica, bandidos que roban a los ricos sin escrúpulo, astrología. No faltaba el mundo de lo sobrenatural, vidas de santos, además de literatura que aun para nuestros modernos criterios alcanzaba grados poco comunes de desenfadada indecencia.

Es un soñar con los ojos abiertos y soñar a "fantasía suelta" sobre la idea de venganza o sobre el valor y la aventura. Estas "historias" y romances contienen todos los elementos capaces de alimentar esas fantasías. Un mundo generoso, optimista, incluso lúdico, surge a menudo de esta literatura popular, que nos hace recordar la frase de Michelet sobre los cuentos de hadas: "[ils] sont le coeur du peuple".

IRIS M. ZAVALA

State University of New York at Stony Brook. 